\title{
Battling against Brown Planthopper in Rice: Genomic Selection in Backcross Breeding to Produce Resistant Cultivars - A Review
}

\author{
R. M. S. K. Rathnayake ${ }^{1}$, S. I. Karunrathne ${ }^{1}$, L. T. Ranaweera ${ }^{1}$, P. G. R. G. Rathnayake ${ }^{1}$, \\ S. D. S. S. Sooriyapathirana ${ }^{*}$
}

${ }^{1}$ Department of Molecular Biology and Biotechnology, Faculty of Science, University of Peradeniya, Peradeniya (20400), Sri Lanka.

\section{Correspondence:}

${ }^{1}$ sunethuop@gmail.com,

iD https://orcid.org/0000-0002-5592-1742

DOI: http://doi.org/10.4038/sljae.v2i2.36

\begin{abstract}
Brown Planthopper (BPH), Nilaparvata lugens Stål, imposes a significant threat to the rice cultivation in Sri Lanka, generating $5-10 \%$ of annual yield losses. Rice farmers mainly adopt chemical methods to control the BPH attacks. The intensive use of insecticides is a crucial trigger for the development of resistance and hence continuous BPH outbreaks. Thus, the chemical methods of control do not provide a permanent solution to the $\mathrm{BPH}$. The most recommended strategy of resolving the $\mathrm{BPH}$ crisis in rice is the development of resistant cultivars. Most of the Sri Lankan rice germplasm has already been screened for BPH resistance; however, reliable molecular breeding strategies must be implemented to acieve this target. Development of BPH resistant cultivars relies on utilizing appropriate genomic selection protocols in breeding schemes such as marker-assisted backcrossing. Therefore, a literature survey was carried out to evaluate BPH control methods and to emphasize the employment of backcross breeding with the genomic selection approach as a precise tool to develop BPH resistant rice varieties. The genetic basis of BPH resistance has been unravelled for many rice cultivars however, further screening is required to identify locally available resistant sources. The polymorphic markers for the foreground and background selection must be developed for the introgression of the BPH resistant genes and recovery of the recurrent parent genome. The validation of the markers developed in the international breeding and genetics programmes for the local germplasm is also an essential step prior to the genomic selection of $\mathrm{BPH}$ resistant rice varieties.
\end{abstract}

Keywords: Backcross breeding, BPH, BPH resistant rice, foreground and background selection, Nilaparvata lugens 


\section{Introduction}

Brown Planthopper (BPH), (Nilaparvata lugens Stål) is one of the most destructive pests in rice farming (Visarto et al. 2001; Matsumura and Morimura 2010). Prolong and persistent outbreaks of $\mathrm{BPH}$ resulting devastating effects have been encountered by rice-growing nations worldwide including Sri Lanka. BPH also renders damage to its host by acting as a carrier for two viruses, Ragged Stunt Virus and Grassy Stunt Virus (Cabauatan et al. 2009; Noda et al. 1991). Since the initial outbreaks, enormous attempts have been made to eradicate the pest; however, a longterm solution is still not available (Tanaka et al. 2000; Senthil-Nathan et al. 2009). BPH has continually evolved resistance against both biological and chemical controlling strategies (Nickel 1964). At present, BPH is immune to insecticides, including neonicotinoids, the most employed $\mathrm{BPH}$ monitoring method (Liu and Han 2006; Wang et al. 2008). However, the chemical treatments are applied in many instances, regardless of safety protocols imposing harmful impacts on both farmers and the public.

Consequently, farmers experience secondary outbreaks and resurgences, mainly because of this continuous application of insecticides without concerning the long-term effects rather than short term solutions (Lim and Heong 1984; $\mathrm{Wu}$ et al. 2004). Most of the techniques employed during insecticide-induced destruction of pests have caused lethal effects on non-target and beneficial organisms further disrupting the ecological balance (Tanaka et al. 2000). Under the given circumstances, BPH resistant rice varieties produced through breeding are recognized as the most reliable solution to tackle the problem (Pathak and Khush 1979; Horgan 2009). Breeding for resistance is currently a more popular approach in comparison to the genetically modified pestresistant crops, which have immense negative perception among the public (Moose and Mumm 2008; Herring 2008; Palmgren et al. 2015). The Sri Lankan rice germplasm has been screened for resistance towards BPH on several occasions and rice varietal improvement has also shown tremendous success throughout the past years. An array of rice varieties (Bw453, At306, Bg250, At307, Bg454, 62_355, At402, Bg403, At362, Bw367, Ld371, Bg310, and Ld253) reported to be resistant to diverse BPH types have also been developed by the Rice Research and Development Institute (RRDI), Bathalagoda (RRDI 2018).

Nevertheless, Marker-Assisted Backcross Breeding (MABB) has not been widely employed in achieving resistance against diverse BPH biotypes up to date. Given the higher adaptability of BPH, it can continue 
developing resistance even against the newly improved varieties emphasizing the need for persistent varietal improvement. Therefore, we reviewed the genetics of $\mathrm{BPH}$ tolerance in rice and the application of backcross breeding to produce BPH tolerant varieties.

\section{Rice varietal resistance for $\mathrm{BPH}$}

The rice varietal resistance has been identified as one of the best economical ways of controlling BPH outbreaks (Pathak 1970; Pathak 1977). Accordingly, the varietal resistance studies on $\mathrm{BPH}$ have commenced in 1969 in various countries such as India (Kalode and Krishna 1979), Japan (Kaneda and Kisimoto 1979), and Solomon Islands (Stapley et al. 1979).
(Sangha et al. 2013). Dependence of varietal resistance on the site of cultivation and the type of resistant rice cultivar have also been studied. Both field and greenhouse trials have been done to determine the levels of resistance (Pathak and Khush 1979) and the resistant genes have been designated based on BPH biotypes (Kabis and Khush 1988) (Table1). Thus, varietal resistance further facilitates the studies on biotypes of BPH. All rice varieties do not have identical resistance to different $\mathrm{BPH}$ biotypes, and the rapid evolution of biotypes hinders the consistency of varietal resistance (Pathak and Khush 1979; Saxena and Barrion 1985).

Table 1. Biotypes of BPH and the genes of resistance.

\begin{tabular}{cccc}
\hline Biotype & Distribution & Resistant gene & Dominance / Recessiveness \\
\hline 1 & South East and East Asia & None & - \\
2 & South East and East Asia & $B p h 1$ & Dominant \\
3 & Sri Lanka & $B p h 2$ & Recessive \\
4 & Indian Subcontinent & $B p h 3$ & Dominant
\end{tabular}

Source: Khush and Brar (1991).

Since then, many entries of the world rice germplasm have been screened for $\mathrm{BPH}$ resistance (Pathak and Khush 1979).

Damage incurred by hopper burn and BPH's population can be used as basic criteria to evaluate the host resistance (Stapley et al. 1979). The degree of rice varietal resistance towards BPH shows a significant variation

\section{$B P H$ resistant mechanisms in host plant}

The resistance of rice varieties against BPH comprises three main mechanisms: antibiosis, tolerance, and antixenosis. These resistance modes are displayed by any host plant, including rice, to deter herbivory (Panda and Heinrichs 1983; Kennedy et al. 
1987; Alam and Cohen 1998a; Qiu et al. 2013).

Antibiosis reveals the reaction of the insect towards the plant (Heinrichs 1986). The metabolism of pest is highly disturbed due to antibiosis (Tingey 1981). Hence, antibiosis resistance is conferred against the biology of the insect (Heinrichs 1986). The major impacts of antibiosis are weakened persistence of insects and lowered rate of reproduction and growth followed by host tissue (Panda and Heinrichs 1983; Kennedy et al. 1987; Qiu et al. 2013).

In contrast, tolerance refers to the response of the plant to the insect (Heinrichs 1986). Tolerance minimizes the intensity of insect damage before reaching the economic threat levels (Kennedy et al. 1987). Loss of the host plant's weight, damage caused, and reduction in the yield are considered key indicators of tolerance (Panda and Heinrichs 1983). Tolerance enables producing a crop of high quality and yield despite insect infestation (Panda and Heinrichs 1983; Kennedy et al. 1987; Qiu et al. 2013).

Non-preference is generally termed as antixenosis (Kogan and Ortman 1978). Nonpreference includes the characters responsible for oviposition and feedingrelated to the pest (Heinrichs 1986); thus, reduces the establishment of the pathogen or oviposition on the host (Panda and Heinrichs 1983; Kennedy et al. 1987; Qiu et al. 2013). Durable resistance can be achieved through tolerance compared to other modalities as it would not cause selection among insects, which prevents the development of new biotypes. Thus, unlike the other two modes, insects' feeding behaviour or health is not affected by tolerance (Panda and Heinrichs 1983; Wu et al. 2014).

\section{Genetics of BPH resistance}

Many rice cultivars express genes conferring either tolerance or antibiosis, while others have both mechanisms (Panda and Heinrichs 1983). Bph6 and Bph12 of Nipponbare (Qiu et al. 2012) and Balamawee (He et al. 2013) have strong antibiosis and antixenotic effects. PtB33 has a high level of antixenosis (Thamarai and Soundararajan 2017), while Bph14 shows antibiosis. DV85 (Du et al. 2009; Qiu et al. 2013), Bph28(t) (Wu et al. 2014) of Kaharamana and, Pokkali display tolerance (He et al. 2013).

Pyramiding the Quantitative Trait Loci (QTLs) with major resistant genes has indicated enhanced resistance in host species. The QTLs associated with antixenosis and antibiosis are not widely known yet. However, a novel QTL associated with antixenosis, Q-Bph8 has been discovered in rice chromosome 8 . Pyramiding of several other BPH resistant 
genes has shown enhanced antixenotic effects (Qiu et al. 2013). There is a greater necessity of investigating the antibiosis and tolerance genes related to BPH resistance, which has not been undertaken in greater depth to date (Qiu et al. 2011).

The breeding strategies are intensely focused on producing varieties resistant to $\mathrm{BPH}$ using tolerance alone or in combination with vertical resistant mechanisms, antixenosis, and antibiosis (Panda and Heinrichs 1983).

\section{Resistant sources}

Development of horizontal resistance, gene pyramiding, multiline varieties, and donor gene identification have allowed the successful accomplishment of the varietal resistance (Saxena and Barrion 1985). Certain BPH resistant genes have been discovered using the microarray analysis (Wang et al. 2012).

The wild rice varieties such as Oryza officinalis, $O$. minuta, and 0 . rufipogon Griff have been identified as critical reserves for BPH resistant genes (Renganayaki et al. 2002; Rahman et al. 2009; Li et al. 2010). $O$. rufipogon has been genetically analysed for its resistant genes Bph2O (t) and Bph21 (t) (Rahman et al. 2009; Huang et al. 2013). Wild species of $O$. sativa is an abundant source of resistant genes that must be readily exploited to screen the genetics of BPH resistance (Jena and Kim 2010).

Apart from wild rice varieties, indica native varieties account for more excellent resistance in comparison to japonica varieties. Fine mapping of these resistant genes from wild rice/indica accessions allows ultimate cloning and breeding schemes. Specific BPH resistant genes have now been fine-mapped (Chen et al. 2006), and map-based cloning of Bph13 ( $t$ ) has been successfully carried out (Renganayaki et al. 2002). Dominant or recessive natures of these genes have been identified (Sidhu and Khush 1978). Diverse resistant mechanisms have been analysed using a protein-based technique to unravel the genes underlying the $\mathrm{BPH}$ resistance (Wei et al. 2009).

Proteins synthesized in response to $\mathrm{BPH}$ attack allow gene cloning and a broader understanding of varietal resistance (Chen et al. 2002). Protein-based approaches are considered more realistic ways of identification of BPH resistant genes through expression analysis of several defence-related proteins (Sangha et al. 2013). Differential expression levels of Expression Sequence Tags (ESTs) have been exploited in mapping BPH resistant genes (Ren et al. 2004). 
The varietal resistance mainly deals with the feeding behaviour of the pest (Cheng et al. 2013). Genes expressed distinctively during $\mathrm{BPH}$ feeding have been identified through Representational Difference Analysis (RDA), which examines the unique expression of Bph genes (Park et al. 2007). Specific and rare genes activated during the feeding of $\mathrm{BPH}$ have also been investigated using the Suppression Subtractive Hybridization (SSH) (Wang et al. 2005). Further, explorations on the BPH salivary gland related genes have been done using the $\mathrm{SSH}$ and Mirror Orientation Selection (MOS) in understanding the expression of defence proteins associated with BPH feeding (Wang et al. 2015).

A comprehensive idea of interactions between $\mathrm{BPH}$ and rice plants must be acquired to improve durably resistant varieties. Thereby, a model has been proposed to explain BPH's molecular-level interactions with rice plants in terms of immunity (Cheng et al. 2013). In the model, a greater varietal resistance has been conferred by combining significant resistance genes with minor resistant genes compared to the sole use of significant genes. The resistance of certain varieties with inherent genes has been evaluated, and the resistance level is further widened by the incorporation of several resistant genes (Saxena and Barrion 1985). Resistant varieties were then screened for pathogen- induced genes such as wound-induced genes and genes involved in the biosynthesis of antioxidants and lignin (Jannoey et al. 2017). The extent of BPH resistance under nutrient enrichment has also been studied by administering micronutrients such as silicon, which showed enhanced resistance levels (He et al. 2015).

\section{Genetics of $B P H$ resistance in rice}

Studies on the genetic basis of resistance were commenced in the early 1960s, along with the research on breeding for resistant cultivars (Kawaguchi et al. 2001). These studies have been recognized as the paths to the most effective solutions for the escalating rates of $\mathrm{BPH}$ outbreaks. Most of the resistance sources are initially found in substandard agronomic backgrounds with insignificant morphological characteristics (Khush 1977).

Diverse programmes have been launched to identify the genes conferring genetics of resistance, their means of inheritance, and the allelic relationships (Khush 1979). Bulk Segregant Analysis (BSA) and linkage analysis have enabled the positioning of the resistance genes to their respective chromosomes (Kawaguchi et al. 2001). Trisomic analysis and techniques such as Fluorescent In-Situ Hybridization (FISH) were readily employed (Jairin et al. 2007). New genes conferring BPH resistance have 
been identified, and these discoveries are beneficial in the development of $\mathrm{BPH}$ resistant cultivars (Khush et al. 1985).

Several studies have been performed to determine the genetics of resistance for specific BPH biotypes. These studies have enabled the detection of BPH resistant genes (Table 1) that can be successfully employed in developing broad-spectrum resistance, achieved by integrating several resistant genes (gene pyramiding) into a single susceptible cultivar (Khush 1977; Khush et al. 1985).

\section{Resistant genes}

Up to date, 21 resistant genes and several QTLs distributed among eight chromosomes have been identified (Alam and Cohen 1998a; Jairin et al. 2007; Jena and Kim 2010). Out of $21 \mathrm{Bph}$ genes, 13 dominant genes, and eight recessive genes have been distinguished (Jena and Kim 2010). Specific BPH resistant genes have shown a switch in its dominance or recessiveness depending on the genetic background (Jairin et al. 2010). The most widely used genes in breeding programmes are $B p h 1, B p h 2, B p h 3$ and, Bph4 (Voramisara and Sa-nguansaj 1994).

Bph1 and Bph2 have been identified linked to each other. while Bph3 and Bph4 are known to be independently segregating
(Khush 1977). Certain resistant varieties are also known to carry more than one resistant genes; PtB33, for example, carries both Bph2 and Bph3 (Jairin et al. 2007). Specific dominant genes, such as Bph4, have been discovered to behave in a recessive manner following the genetic background (Jairin et al. 2010). Eighteen of the genes are distributed in six of the 12 chromosomes of rice, most of them forming distinct clusters (Jena and Kim 2010; Liu et al. 2015). Six genes stemmed from wild Oryza species encompass either duplicated locations in their respective chromosomes or inaccuracies in their nomenclature (Jena and Kim 2010; $\mathrm{Hu}$ et al. 2016). Bph14 and Bph18 have been cloned as well (Jena et al.2006; Du et al. 2009; Jena and Kim 2010).

The BPH-resistant genes investigated are from different genetic bases, including landraces and Oryza's wild relatives (Ikeda et al. 1994; Yang et al. 2002; Jena and Kim 2010). Most of the BPH resistant varieties possess low agronomic traits such as greater plant height, drooping leaves, and fragile stems and have lower yields.

Thus, the resistant genes must be transferred successfully to the improved and high yielding varieties (Khush 1977). Once the resistance genes are identified, marker-assisted gene pyramiding can be performed (Sun et al. 2005). Many such 
genes have been incorporated into mega or more popular rice varieties (Khush et al. 2001) leading to the production of multiline varieties with prolonged overall resistance. Some markers are tightly linked to resistant genes, which provides avenues for $\mathrm{MAB}$ strategies to develop $\mathrm{BPH}$ resistance in susceptible cultivars (Jairin et al. 2007). Gene pyramiding can thus be expanded to efficient use of tightly linked Simple Sequence Repeat (SSR) markers (Jena and Mackill 2008).

Linkage and allelic relationships must be thoroughly investigated in the successful development of resistant cultivars of rice (Jena and Kim 2010). The latest research studies on BPH genetics and other important details are listed in Table 2.

\section{Breeding for BPH Resistance}

Breeding programmes against $\mathrm{BPH}$ are conducted worldwide to release resistant varieties. Breeding for BPH resistance was initiated in 1967 in conjunction with screening for resistant cultivars (Heinrichs 1986). These efforts have been immensely supported by the whole genome sequence of rice made accessible by the Rice Genome Sequencing Project (Fujisawa et al. 2005). However, breeding for resistance is hampered by the constant evolution of biotypes, absence of effective screening procedures, issues related to the selection of donors, improper trait combinations within donors, and low consumer preference for the newly bred pest-resistant varieties. Besides, breeding strategies depend on the attributes of the area of cultivation (Heinrichs 1986). Thus, mutual efforts of breeders and genomic scientists are indispensable for further developments of the specific discipline. Most breeding plans exploit the greater diversity of wild rice varieties since they can thrive in many habitats and are not under frequent human selection. Analysis of several crucial genes of many wild rice accessions has also been facilitated by the Oryza Map Alignment Project (OMAP) (Ammiraju et al. 2006).

Major steps in breeding for resistance involve manipulating genes responsible and their successful incorporation into susceptible cultivars via MAS or gene pyramiding (Brar et al. 2009). Introgression lines (ILs) also play a prominent role in backcross breeding in providing breeding materials for developing genetically stable mega varieties and gene pyramiding (Ali et al. 2006). The breeding programmes are further accelerated by the QTLs that govern significant traits. Also, the pyramiding of QTLs can be performed to produce BPH resistant varieties (Ammiraju et al. 2006). Current biotech tools have permitted breeders to locate valuable commercial varieties, landraces, or wild relatives (Negrao et al. 2008). 'Smart breeding' that 
employs natural variations of genes inbreeding (McCouch 2004) and 'Breeding by Design' (Peleman and van der Voort 2003) that exploits the allelic variations to design better-quality genotypes are famous as the modern trends in breeding for resistance.

Table 2. The advances in the field of BPH research

\section{Backcross breeding}

Backcross breeding is a standard approach of plant breeding (Allard 1960) that could be readily employed to introgress $\mathrm{BPH}$

\begin{tabular}{|c|c|}
\hline Major Research Outcome & Reference/s \\
\hline $\begin{array}{l}\text { Screening of rice varieties for resistance revealing novel BPH resistant } \\
\text { genes }\end{array}$ & $\begin{array}{l}\text { Athwal et al. (1971); Khush } \\
\text { (1979); Kim and Sohn (2005) }\end{array}$ \\
\hline $\begin{array}{l}\text { Identification of locations of } B p h \text { genes in rice Chromosome (Bph9) and } \\
\text { the intricately linked molecular markers }\end{array}$ & Chang et al. (2006) \\
\hline $\begin{array}{l}\text { Mapping of } B p h \text { genes (Bph2) and marker-assisted breeding to breed } \\
\text { BPH resistant varieties }\end{array}$ & Li et al. (2006) \\
\hline Exploitation of phenotype-based approaches for screening & Jairin et al. (2010) \\
\hline $\begin{array}{l}\text { Investigation of traditional rice varieties such as Salkathi for novel QTLs } \\
\text { of BPH resistance }\end{array}$ & $\begin{array}{l}\text { Brar et al. (2009); Mohanty et al. } \\
\text { (2017) }\end{array}$ \\
\hline $\begin{array}{l}\text { Marker analysis done mostly using SSR markers to explore resistant } \\
\text { genes }\end{array}$ & Kumari et al. (2010) \\
\hline Marker assisted selection (MAS) of BPH resistant cultivar & Suh et al. (2011) \\
\hline $\begin{array}{l}\text { Mapped out of location of } B p h \text { genes in the rice chromosomes with } \\
\text { exception of } B p h 5 \text { and } B p h 8\end{array}$ & $\begin{array}{l}\text { Hou et al. (2011); Yang et al. } \\
\text { (2012); Cheng et al. (2013); Hu et } \\
\text { al. (2016); Jing et al. (2017) }\end{array}$ \\
\hline Introgression of $B p h$ genes into the susceptible rice cultivars & $\begin{array}{l}\text { Wan et al. (2014); Jena et al. } \\
(2017)\end{array}$ \\
\hline $\begin{array}{l}\text { Simultaneous research attempts on BPH using sophisticated } \\
\text { technologies such as Next Gen Sequencing }\end{array}$ & Wan et al. (2014) \\
\hline $\begin{array}{l}\text { Map based cloning of Bph genes (Bph29, Bph18 and Bph26) followed by } \\
\text { successful characterization }\end{array}$ & $\begin{array}{l}\text { Tamura et al. (2014); Wang et al. } \\
\text { (2015); Ji et al. (2016) }\end{array}$ \\
\hline $\begin{array}{l}\text { Employment of breeding strategies that make use of allelic diversity of } \\
\text { Bph gene clusters }\end{array}$ & Zhao et al. (2016) \\
\hline $\begin{array}{l}\text { QTL analysis to identify and map the resistant breaking genes of BPH } \\
\text { that are active against the anti-feeding mechanism of rice resistant gene }\end{array}$ & Kobayashi et al. (2014) \\
\hline $\begin{array}{l}\text { Mapping and MAS of Bph genes (Bph2) to produce BPH resistant } \\
\text { varieties }\end{array}$ & $\begin{array}{l}\text { Kaur et al. (2015); Suh et al. } \\
\text { (2015) }\end{array}$ \\
\hline Fine mapping and pyramiding of genes such as $Q b p h 3$ and $Q b p h 4$ & Hu et al. (2015) \\
\hline Allelic diversity studies of resistant genes (Bph18) & Ramkumar et al. (2016) \\
\hline $\begin{array}{l}\text { Successful adoption of MABB to develop NILs using the resistant } \\
\text { cultivars }\end{array}$ & Xiao et al. (2016) \\
\hline $\begin{array}{l}\text { Detection of major } B p h \text { resistant genes ( } 31 \text { up to date) in both indica } \\
\text { and wild rice varieties }\end{array}$ & Jing et al. (2017) \\
\hline $\begin{array}{l}\text { The associations between } \mathrm{BPH} \text { and its host plant, rice have been } \\
\text { experimented broadly as a typical simulation in deciphering host plant } \\
\text { interactions }\end{array}$ & Jing et al. (2017) \\
\hline $\begin{array}{l}\text { Fine mapping of genes including Bph31 and pyramiding of other genes } \\
\text { such as Bph3 and Bph27 }\end{array}$ & Prahalada et al. (2017) \\
\hline $\begin{array}{l}\text { Fine mapping of certain broad-spectrum resistant genes, their } \\
\text { introgression into a mega variety and subsequent analysis of gene } \\
\text { expression }\end{array}$ & Prahalada et al. (2017) \\
\hline Cloning of four Bph resistant genes (Bph14, Bph26, Bph18 and Bph9) & Liu et al. (2015); Jing et al. (2017) \\
\hline
\end{tabular}


resistant genes from landraces into elite cultivars. Backcross breeding involves incorporating foreign germplasm from a closely related cultivar, with undesirable traits into a crop cultivar of economic and/or agronomic importance (Brown et al. 1989). Backcross breeding is beneficial in breeding programmes in which the donor parent possesses a greater number of undesirable traits (Hagiwara et al. 2001). Recurrent backcrossing is considered as the traditional aspect of this technique (Hasan et al. 2015).

Gene integration using this strategy is a comparatively slow procedure (Stam 1981). This method especially poses a problem in the recovery of recessive alleles, which is tedious (Brown et al. 1989). The linkage drag hinders the successful recovery of the desired allele during the backcross breeding. Thus, markers that assist in the foreground and background selection are readily employed in the modern recurrent backcrossing schemes to reduce the linkage drag (Frisch et al. 1999). Thereby, it renders the conventional backcross procedure more laborious (Wissuwa et al. 2002). Consequently, overall efficiency must be increased by employing markers in the selection of backcrossed progeny. This procedure is termed as Marker Assisted Backcross Breeding (MABB) (Frisch et al. 1999).
MABB exploits markers' potential to identify resistant genes that account for favourable traits such as durable resistance to abiotic and biotic stresses (Hasan et al. 2015).

Backcross breeding can be done in combination with conventional selection methods to produce rice cultivars resistant to abiotic stresses such as drought (Lafitte et al. 2006). The procedure has been successfully carried out in developing host plant resistance in wheat against commonly found rust diseases using a single backcross breeding approach (Singh et al. 2005). It has even been carried out for higher plants, which include the revival of American Chestnut Tree, eliminated by blight (Hebard 2006). MABB has also been successfully carried out for specific barley cultivars resistant to the yellow dwarf virus (Tester and Langridge 2010) and to increase food quality parameters in soybeans (Maranna et al. 2016) and to improve the cooking quality of rice (Kwon et al. 2011). Nevertheless, backcrossing cannot be applied effectively for many other crops due to the absence of DNA marker systems, causing them to lag forward genetic approaches. Backcrossing cannot perform for vegetatively propagated crops and species with long regeneration times and high heterozygosity (Bradford et al. 2005). However, given the wealth of genomic information available for rice, MABB can be readily employed to produce $\mathrm{BPH}$ resistant rice varieties (Fig. 1). 


\section{Foreground selection}

Foreground selection is defined as selecting individuals that carry the genes of the donor parent (for example, BPH resistant gene) with the assistance of the markers to guarantee the presence of genes without being lost during the backcross (Fig. 1). The presence of the desired donor genes in the recombinant genome is confirmed by linked markers (Jun-Yan et al. 2006). QTL segments of the crossed populations are analysed for the donor like alleles (Lecomte et al. 2004). The potential use of markers for background and foreground selection in backcross breeding programs has been well studied (Hospital and Charcosset 1997). Tightly linked or flanked markers enable efficient foreground selection (Jun-Yan et al. 2006). Flanking markers facilitate the reduction of linkage drag while linked markers validated across different parental combinations allow excellent recovery of recurrent parent traits (Gopalakrishnan et al. 2008).

A minimum of three markers must be used to achieve successful foreground selection (Hospital and Charcosset 1997). Foreground selection through phenotypically active functional markers is more feasible than that of phenotypically neutral random DNA markers. Single nucleotide polymorphism (SNP), SSR, Cleaved Amplified Polymorphism (CAP), Single Feature Polymorphism (SFP), Restriction-site
Associated DNA (RAD) and, Diversity Array Technology (DArT) are random genetic markers currently available for foreground selection (Wenzl et al. 2004; Hazen et al. 2005; Gupta et al. 2010). Nevertheless, functional markers are comparatively more effective (Bagge and Lübberstedt 2008). Foreground selection is categorized as direct selection and indirect selection. Indirect selection uses a single linked marker or two flanking makers during selection (Jun-Yan et al. 2006). Foreground selection using markers is an alternative to the direct phenotypic evaluation, which is time-consuming, inflated, and unfeasible (Hospital and Charcosset 1997).

However, foreground selection can be executed simultaneously with the phenotypic selection, an inexpensive strategy that allows the rapid identification of introgressed lines (Suh et al. 2013). Initial foreground selection and subsequent thinning of the number of individuals used for the foreground selection are less costly, mainly when several QTLs are analyzed (Hospital and Charcosset 1997). Foreground selection followed by background selection has been successfully carried out for the development of NILs of disease-resistant soybeans (Kim et al. 2008).

\section{Background selection}

Background selection is defined as selecting the genetic background of the individuals 
who receive the desired gene (for example, $\mathrm{BPH}$ resistant gene) from a donor parent (Fig. 1). It is supported by the evidence from molecular or phenotypic markers, which enhance the rate of retrieval of its genetic background (Jun-Yan et al. 2006). Thereby, it ensures the recovery of the recombinants of a progeny that possessesthe recurrent parent genome (Gopalakrishnan et al. 2008). Plants that display the nearest genetic background to that of the recipient parent are thus designated (Lecomte et al. 2004). Background selection allows retrieving the genome outside the QTL regions of interest (Hospital and Charcosset 1997).

The methodology can be categorized into three major approaches; random selection, genomic similarity selection, and marker index selection (Jun-Yan et al. 2006). The efficacy of background selection and the subsequent genome recovery is further improved using markers. Hence, the possible use of markers for background selection in backcross breeding programs has been thoroughly investigated (Hospital and Charcosset 1997). The DNA markers used are polymorphic between two donors and recurrent parents (Neeraja et al. 2007). Efficient background selection can be carried out using mapped molecular markers, either flanked or tightly linked to the desired gene (Jun-Yan et al. 2006). Amplified Fragment Length Polymorphism (AFLP), DArT, and SSR markers have been frequently used in background selection (Thabuis et al. 2004; Gupta et al. 2010). Nevertheless, specific PCR based markers are inefficient in background selection, as they require many marker data points to recover the desirable quality traits in recombinants. Recovery of the whole genetic background requires genomic similarity selection or marker-index selection (Jun-Yan et al. 2006).

This approach involves the distribution of markers on the entire genome, which is less feasible and costly. Thus, consideration of only the economically valuable traits for selection has been identified as a less expensive tactic. Background selection is carried out for both carrier and non-carrier chromosomes, for only a limited number of individuals resulting from initial foreground selection (Hospital and Charcosset 1997). Multi-step background selection with two or more selection steps is identified more effective (Gupta et al. 2010).

The background genome recovery percentage can be calculated after the background selection (Suh et al. 2013). Background selection can be very efficiently employed in back crossbreeding programs (Hospital and Charcosset 1997). It can be carried out in a backcross breeding program where several QTLs are analysed for pyramiding (Suh et al. 2013). 
Donor parent genome

$\mathrm{Chr}$

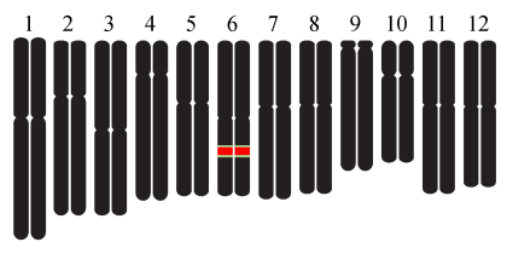

Recurrent parent genome

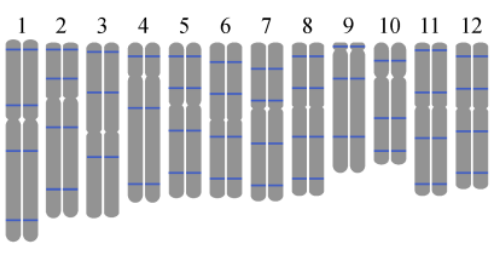

F1

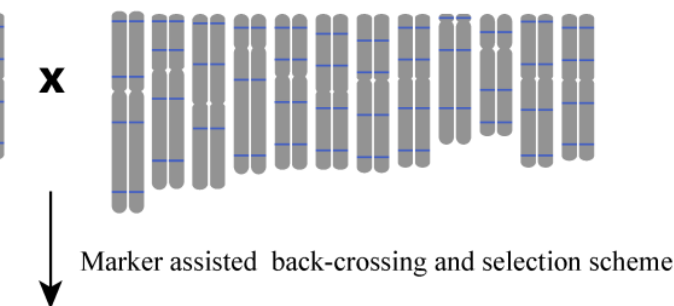

Combinations observed in BC1 (Three examples of the infinite number of combinations observed in BC1)

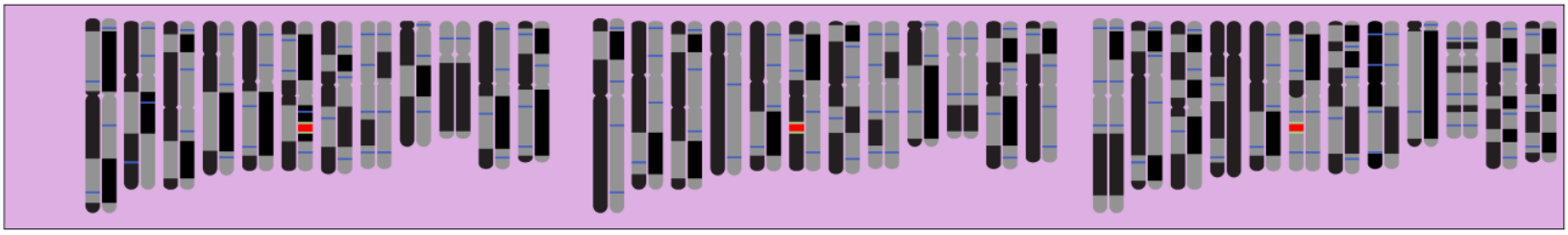

Simultaneous foreground and background selection

$\downarrow$
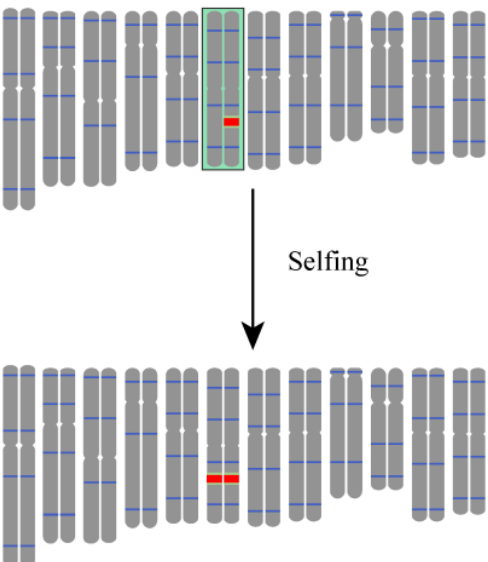

The selected genome of the progeny (i.e. Bph tolerant variety with recurrent genome)

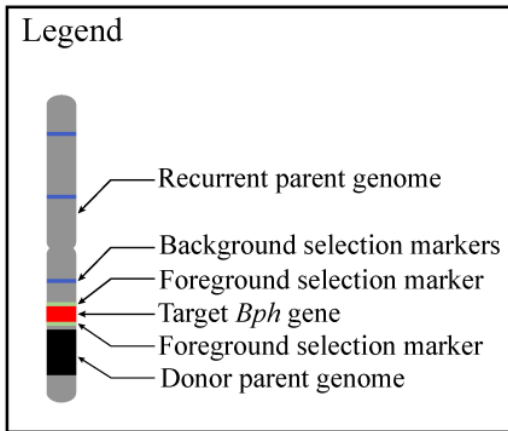

Figure 1. A diagram on the foreground and background selection scheme for developing a BPH resistant cultivar through recurrent backcrossing. The donor parent genome (black) residing the gene of interest (red) from a local landrace resistant to BPH is crossed with the recurrent parent genome (grey) from an improved mega variety which is sensitive to BPH attack. Foreground selection is carried out via two foreground markers (light green) flanking the gene of interest. Simultaneous background selection is carried out by employment of a large number of background markers chosen to cover the whole length of each of the twelve rice chromosomes. The confirmation of hybridity is carried out with the use of the background and foreground markers. Subsequently, a marker-assisted selection scheme with repeated backcrossing is implemented across several generations for the selection of the target donor gene via foreground selection and selection of the recurrent parent genome via background selection. The progeny plants with the successful introgression of the donor gene and the highest recovery of the recurrent parent genome are selected and selfed. The independent segregation of the selfed progeny results in homozygous progeny plants with BPH resistance. 


\section{Conclusions}

Despite the attempts to improve the agronomic quality of rice, MABB has not been widely employed for the development of BPH resistant varieties. This review of the research studies on the varietal improvement for BPH resistance conveys the need for rigorous search of polymorphic markers for the foreground and background selection, which allows successful introgression of the BPH resistant genes and recovery of the recurrent parent genome resulting in commercial cultivars that are resistant to $\mathrm{BPH}$ attacks. A number of markers, especially employable in background selection schemes, must be widened in making the procedure more effective. The review further concludes that the other means of control of BPH, especially the chemical means, are not favourable in terms of rice cultivation and farmers' livelihood. However, it is further emphasized that the simultaneous deployment of biological and cultural methods or the integrated management strategies and the varietal improvement will generate more fruitful outcomes. In order to achieve the above goals, the farming communities must be made aware, and Breeders' Guides can be prepared in popularizing the MABB programs as a key mode of breeding for BPH resistance.

\section{Acknowledgments}

University of Peradeniya, Sri Lanka (2016) Research Grant (No.: URG/2016/59/S).

Conflicts of Interest: The authors declare that there are no conflicts of interest regarding the publication of this paper.

\section{References}

Alam S N, Cohen M B (1998a) Detection and analysis of QTLs for resistance to the brown planthopper Nilaparvata lugens in a doubled-haploid rice population. Theor Appl Genet 97:370-1379.

Ali A J, Xu J L, Ismail A M, Fu B Y, Vijaykumar C H M, Gao Y M, Domingo J, Maghirang R, Yu S B, Gregorio G, Yanaghihara S (2006) Hidden diversity for abiotic and biotic stress tolerances in the primary gene pool of rice revealed by a large backcross breeding programme. Field Crops Res 97: 66-76.

Allard R W (1960) Principles of plant breeding. Wiley Publications, New York. p.485.

Ammiraju J S, Luo M, Goicoechea J L, Wang W, Kudrna D, Mueller C, Talag J, Kim H, Sisneros N B, Blackmon B, Fang E (2006) The Oryza bacterial artificial chromosome library resource: construction and analysis of 12 deep-coverage large-insert BAC 
libraries that represent the 10 genome types of the genus Oryza. Genome Res 16:140-147.

Athwal D S, Pathak M D, Bacalangco E H, Pura C D (1971) Genetics of resistance to brown planthoppers and green leafhoppers in Oryza sativa L. Crop Sci 11:747-750.

Bagge M, Lubberstedt T (2008) Functional markers in wheat: technical and economic aspects. Mol Breed 22: 319-328.

Bradford K J, Van Deynze A, Gutterson N, Parrott W, Strauss S H (2005) Regulating transgenic crops sensibly: lessons from plant breeding, biotechnology and genomics. Nat Biotechnol 23: 439.

Brar D S, Virk P S, Jena K K, Khush G S (2009) Breeding for resistance to planthoppers in rice in Heong KL, Hardy B (Eds.) Planthoppers: new threats to the sustainability of intensive rice production systems in Asia, International Rice Research Institute, Los Baños, Philippines. Pp.409.

Brown A H D, Lawrence G J, Jenkin M, Douglass J, Gregory E (1989) Linkage drag in backcross breeding in barley. J Hered 80: 234-239.

Cabauatan P Q, Cabunagan R C, Choi I R, Heong K L L, Hardy B (2009) Planthoppers: new threats to the sustainability of intensive rice production systems in Asia by KL Heong and B. Hardy, IRRI, Los Baños, pp.357-368.

Chang C S, Hu Q Z, Chun M W, Li H S, Jian M W (2006) SSR mapping of brown planthopper resistance gene Bph9 in Kaharamana, an indica rice (Oryza sativa L.). J Genet Genomics 33:262-268.

Chen J W, Wang Pang X F, Pan Q H (2006) Genetic analysis and fine mapping of a rice brown planthopper (Nilaparvata lugens Stål) resistance gene $\operatorname{bph} 19$ (t). Mol Genet Genomics 275:321-329.

Chen R Z, Weng Q M, Huang Z, Zhu L L, He G C (2002) Analysis of resistance-related proteins in rice against brown planthopper by two-dimensional electrophoresis. J Integr Plant Biol 44: 427-432.

Cheng X, Zhu L, He G (2013) Towards understanding of molecular interactions between rice and the brown planthopper. Mol Plant 6:621-634.

Du B, Zhang W, Liu B, Hu J, Wei Z, Shi Z, He R, Zhu L, Chen R, Han B, He G (2009) Identification and characterization of Bph14, a gene conferring resistance to brown planthopper in rice. Proc Natl Acad Sci 106:22163-22168. 
Frisch M, Bohn M, Melchinger A E (1999) Comparison of selection strategies for marker-assisted backcrossing of a gene. Crop Sci 39: 1295-1301.

Gopalakrishnan S, Sharma R K, Anand Rajkumar K, Joseph M, Singh V P, Singh A K, Bhat K V, Singh N K, Mohapatra T (2008) Integrating marker assisted background analysis with foreground selection for identification of superior bacterial blight resistant recombinants in Basmati rice. Plant Breed 127:131-139.

Gupta P K, Kumar J, Mir R R, Kumar A (2010) Marker-Assisted Selection as a component of conventional plant breeding. Plant Breed Rev 33:145.

Hagiwara W E, Santos J D, Carmo S D (2001) Use of RAPD to aid selection in common bean backcross breeding programs. Crop Breed Appl Biot 1:355-362.

Hasan M M, Rafii M Y, Ismail M R, Mahmood M, Rahim H A, Alam M A, Ashkani S, Malek M A, Latif M A (2015) Marker-assisted backcrossing: a useful method for rice improvement. Biotechnol Biotechnol Equip 29:237-254.

Hazen S P, Borevitz J O, Harmon F G, Pruneda-Paz, J L, Schultz T F, Yanovsky M J,
Liljegren S J, Ecker J R, Kay S A (2005) Rapid array mapping of circadian clock and developmental mutations in Arabidopsis. Plant Physiol 138: 990-997.

He J, Liu Y, Liu Y, Jiang L, Wu H, Kang H, Liu S, Chen L, Liu X, Cheng X, Wan J (2013) Highresolution mapping of brown planthopper $(\mathrm{BPH})$ resistance gene $B p h 27(\mathrm{t})$ in rice (Oryza sativa L.). Mol Breed 31:549-557.

He W, Yang M, Li Z, Qiu J, Liu F, Qu X, Qiu Y, Li R (2015) High levels of silicon provided as a nutrient in hydroponic culture enhances rice plant resistance to brown planthopper. Crop Prot 67: 20-25.

Hebard F V (2006) The backcross breeding program of the American Chestnut Foundation. Journal of the American Chestnut Foundation :55-77.

Heinrichs E A (1986) Perspectives and directions for the continued development of insect-resistant rice varieties. Agr Ecosyst Environ 18:9-36.

Herring R J (2008) Opposition to transgenic technologies: ideology, interests and collective action frames. Nat Rev Genet 9:458-463.

Horgan F (2009) Mechanisms of resistance: a major gap in understanding planthopper- 
rice interactions in Heong $\mathrm{K}$ L, Hardy $\mathrm{B}$ Planthoppers: New threats to the sustainability of intensive rice production systems in Asia, International Rice Research Institute, Los Baños, Philippines. Pp 281-302.

Hospital F, Charcosset A (1997) MarkerAssisted introgression of Quantitative Trait Loci. Genetics 147:1469.

Hou L Y, Yu P, Xu Q, Yuan X P, Yu H Y, Wang Y P, Wang C H, Wan G, Tang S X, Peng S T (2011) Genetic analysis and preliminary mapping of two recessive resistance genes to brown planthopper, Nilaparvata lugens Stål in rice. Rice Sci 18:238-242.

Hu J, Xiao C, He Y (2016) Recent progress on the genetics and molecular breeding of brown planthopper resistance in rice. Rice 9:1-12.

Hu J, Xiao C, Cheng M, Gao G, Zhang Q, He Y (2015) Fine mapping and pyramiding of brown planthopper resistance genes $Q B p h 3$ and $Q B p h 4$ in an introgression line from wild rice O. officinalis. Mol Breed 35(1):3.

Huang D, Qiu Y, Zhang Y, Huang F, Meng J, Wei S, Li R, Chen B (2013) Fine mapping and characterization of $B P H 27$, a brown planthopper resistance gene from wild rice
(Oryza rufipogon Griff.). Theor Appl Genet 126:219-229.

Ikeda R, Vaughan D, Kobayashi N (1994) Landraces and wild relatives of rice [Oryza sativa] as sources of useful genes. JIRCAS International Symposium Series; Japan: 620.

Jairin J, Phengrat K, Teangdeerith S, Vanavichit A, Toojinda T (2007) Mapping of a broad-spectrum brown planthopper resistance gene, Bph3, on rice chromosome 6. Mol Breed 9:35-44.

Jairin J, Sansen K, Wongboon W, Kothcharerk J (2010) Detection of a brown planthopper resistance gene $b p h 4$ at the same chromosomal position of Bph3 using two different genetic backgrounds of rice. Breed Sci 60:71-75.

Jannoey P, Channei D, Kotcharerk J, Pongprasert W, Nomura M (2017) Expression analysis of genes related to rice resistance against brown planthopper, Nilaparvata lugens. Rice Sci 24:163-172.

Jena K K, Hechanova S L, Verdeprado H, Prahalada G D, Kim S R (2017) Development of 25 near-isogenic lines (NILs) with ten $\mathrm{BPH}$ resistance genes in rice (Oryza sativa L.): Production, resistance spectrum, and molecular analysis. Theor Appl Genet 130:116. 
Jena K K, Kim S M (2010) Current status of brown planthopper (BPH) resistance and genetics. Rice 161-171.

Jena K K, Jeung J U, Lee J H, Choi H C, Brar D S (2006) High-resolution mapping of a new brown planthopper (BPH) resistance gene, $B p h 18(\mathrm{t})$, and marker-assisted selection for $\mathrm{BPH}$ resistance in rice (Oryza sativa L.). Theor Appl Genet 112:288-297.

Jena K K, Mackill D J (2008) Molecular markers and their use in marker-assisted selection in rice. Crop science 48(4), pp.1266-1276.

Ji H, Kim S R, Kim Y H, Suh J P, Park H M, Sreenivasulu N, Misra G, Kim S M, Hechanova S L, Kim H, Lee G S (2016) Map-based cloning and characterization of the $B P H 18$ gene from wild rice conferring resistance to brown planthopper (BPH) insect pest. Sci Rep 6:34376.

Jing S, Zhao Y, Du B, Chen R, Zhu L, He G (2017) Genomics of interaction between the brown planthopper and rice. Curr Opin Insect Sci 19:82-87.

Jun-Yan Bai, Qin Zhang, Xiao-Ping Jia (2006) Comparison of different foreground and background selection methods in marker- assisted introgression. J Genet Genomics 33:1073-1080.

Kabis A, Khush G S (1988) Genetic analysis of resistance to brown planthopper in rice (Oryza sativa L.). Plant Breed 100:54-58.

Kalode M B, Krishna T S (1979) Varietal resistance to brown planthopper in India in Heong K L, Hardy B (Eds.) Brown planthopper: Threat to rice production in Asia, International Rice Research Institute, Los Banõs, Phillippines. Pp. 187-199.

Kaneda C, Kisimoto R (1979) Status of varietal resistance to brown planthopper in Japan in Heong K L, Hardy B (Eds.) Brown Planthopper: Threat to Rice Production in Asia, International Rice Research Institute, Los Banõs, Phillippines. Pp. 209-218.

Kaur S, Panesar P S, Bera M B, Kaur V (2015) Simple sequence repeat markers in genetic divergence and marker-assisted selection of rice cultivars: a review. Crit Rev Food Sci Nutr 55:41-49.

Kawaguchi M, Murata K, Ishii T, Takumi S, Mori N, Nakamura C (2001) Assignment of a brown planthopper (Nilaparvata lugens Stål) resistance gene $b p h 4$ to the rice chromosome 6. Breed Sci 51:13-18.

Kennedy G G, Gould F, Deponti O M B, Stinner RE (1987) Ecological, agricultural, genetic, 
and commercial considerations in the deployment of insect-resistant germplasm. Environ Entomol 16:327-338.

Khush G S (1977) Breeding for resistance in rice. Ann N Y Acad Sci 287:296-308.

Khush G S (1979) Genetics of and breeding for resistance to the brown planthopper in Heong K L, Hardy B (Eds.) Brown planthopper: Threat to rice production in Asia, International Rice Research Institute, Los Baños, Philippines. Pp. 321-332.

Khush G S, Brar D S (1991) Genetics of resistance to insects in crop plants. Advances in Agronomy 45: 223-274.

Khush G S, Coffman W R Beachell H M M (2001) The history of rice breeding: IRRI's contribution. Rice research and production in the 21st century: Symposium honouring Robert F. Chandler Jr, International Rice Research Institute Manila, Philippines. Pp. 117-135.

Khush G S, Karim A R, Angeles E R (1985) Genetics of resistance of rice cultivar ARC10550 to Bangladesh brown planthopper biotype. J Genet 64:121-125.

Kim K H, Kim M Y, Van K, Moon J K, Kim D H, Lee S H (2008) Marker-assisted foreground and background selection of near isogenic lines for bacterial leaf pustule resistant gene in soybean. J Crop Sci Biotechnol 11:263268.

Kim S M, Sohn J K (2005) Identification of a rice gene $(B p h$ 1) conferring resistance to brown planthopper (Nilaparvata lugens Stal) using STS markers. Mol Cell 20:1-5.

Kobayashi T, Yamamoto K, Suetsugu Y, Kuwazaki S, Hattori M, Jairin, J, SanadaMorimura S, Matsumura M (2014) Genetic mapping of the rice resistance-breaking gene of the brown planthopper Nilaparvata lugens. Proc R Soc Lond B Biol Sci 281:2.

Kogan M, Ortman E F (1978) Antixenosis-a new term proposed to define Painter's "non -preference" modality of resistance. Bull Ecol Soc Am 24:175-176.

Kumari S, Sheba J M, Marappan M, Ponnuswamy S, Seetharaman S, Pothi N, Subbarayalu M, Muthurajan R, Natesan S (2010) Screening of IR50× Rathu Heenati F7 RILs and identification of SSR markers linked to brown planthopper (Nilaparvata lugens Stål) resistance in rice (Oryza sativa L.). Mol Biotechnol 46:63-71.

Kwon S W, Cho Y C, Lee J H, Suh J P, Kim J J, Kim M K, Choi I S, Hwang H G, Koh H J, Kim Y G (2011) Identification of quantitative trait loci associated with rice eating quality traits 
using a population of recombinant inbred lines derived from a cross between two temperate japonica cultivars. Mol Cells 31:437-445.

Lafitte H R, Li Z K, Vijayakumar C H M, Gao Y M, Shi Y, Xu J L, Fu B Y, Yu S B, Ali A J, Domingo J, Maghirang R (2006) Improvement of rice drought tolerance through backcross breeding: evaluation of donors and selection in drought nurseries. Field Crops Res 97: 77-86.

Lecomte L, Duffe P, Buret M, Servin B, Causse M (2004) Marker-assisted introgression of five QTLs controlling fruit quality traits into three tomato lines revealed interactions between QTLs and genetic backgrounds. Theor Appl Genet 109:658668.

Li H S, Chun M W, Chang C S, Yu Q L, Hu Q Z, Jian M W (2006) Mapping and markerassisted selection of a brown planthopper resistance gene bph2 in rice (Oryza sativa L.). J Genet Genomics 33:717-723.

Li R, Li L, Wei S, Wei Y, Chen Y, Bai,D. Yang,L, Huang F, Lu W, Zhang X, Li X (2010) The evaluation and utilization of new genes for brown planthopper resistance in common wild rice (Oryza rufipogon Griff.). Mol Entomol 1:1-4.
Lim G S, Heong K L (1984) The role of insecticides in rice integrated pest management. Proceedings of the FAO/lRRl workshop on judicious and efficient use of insecticides on rice; Los Banos, Philippines. Pp. 19-40.

Liu Y, Wu H, Chen H, Liu Y, He J, Kang H, Sun Z, Pan G, Wang Q, Hu J, Zhou F (2015) A gene cluster encoding lectin receptor kinases confers broad-spectrum and durable insect resistance in rice. Nat Biotechnol 33: 301305.

Liu Z, Han Z (2006) Fitness costs of laboratory-selected imidacloprid resistance in the brown planthopper, Nilaparvata lugens Stål. Pest Manag Sci 62:279-282.

Maranna S, Verma K, Talukdar A, Lal S K, Kumar A, Mukherjee K (2016) Introgression of null allele of Kunitz trypsin inhibitor through marker-assisted backcross breeding in soybean (Glycine max L. Merr.). BMC Genomics 17:106.

Fujisawa M, Baba T, Nagamura Y, Nagasaki H, Waki K, Vuong H, Matsumoto T, Wu J Z, Kanamori H, Katayose Y 2005. The mapbased sequence of the rice genome. Nature 436: 793-800

Matsumura M, Sanada-Morimura S (2010) Recent status of insecticide resistance in 
Asian rice planthoppers. Jpn Agr Res Q 44:225-230.

McCouch S (2004) Diversifying selection in plant breeding. PLoS Biol 2:347.

Mohanty S K, Panda R S, Mohapatra S L, Nanda A, Behera L, Jena M, Sahu RK, Sahu S C, Mohapatra T (2017) Identification of novel quantitative trait loci associated with brown planthopper resistance in the rice landrace Salkathi. Euphytica 213:38.

Moose S P, Mumm R H (2008) Molecular plant breeding as the foundation for 21st century crop improvement. Plant Physiol 147:969-977.

Neeraja C N, Maghirang-Rodriguez R, Pamplona A, Heuer S, Collard B C Y, Septiningsih E M, Vergara G, Sanchez D, Xu K, Ismail A M, Mackill D J (2007) A markerassisted backcross approach for developing submergence-tolerant rice cultivars. Theor Appl Genet 115:767-776.

Negrao S, Oliveira M M, Jena K K, Mackill D (2008) Integration of genomic tools to assist breeding in the japonica subspecies of rice. Mol Breed 22:159-168.

Nickel J L (1964) Biological control of rice stem borers: a feasibility study (2).
International Rice Research Institute, Los Baños, Philippines.

Noda $\mathrm{H}$, Ishikawa $\mathrm{K}$, Hibino $\mathrm{H}$, Omura T (1991) A reovirus in the brown planthopper, Nilaparvata lugens. J Gen Viro 172:24252430.

Palmgren M G, Edenbrandt A K, Vedel S E, Andersen M M, Landes X, Osterberg J T, Falhof J, Olsen L I, Christensen S B, Sandoe P, Gamborg C (2015) Are we ready for back-tonature crop breeding? Trends Plant Sci 20:155-164.

Panda N, Heinrichs E A (1983) Levels of tolerance and antibiosis in rice varieties having moderate resistance to the brown planthopper, Nilaparvata lugens (Stål) (Hemiptera: Delphacidae). Environmental Entomology 12(4). pp.1204-1214.

Park D S, Lee S K, Lee J H, Song M Y, Song S Y, Kwak D Y, Yeo U S, Jeon N S, Park S K, Yi G Song Y C (2007) The identification of candidate rice genes that confer resistance to the brown planthopper (Nilaparvata lugens) through representational difference analysis. Theor Appl Genet 115:537-547.

Pathak M D (1970) Genetics of plants in pest management. In: Concepts of Pest Management, Academic Press, USA. Pp. 138157. 
Pathak M D (1977) Defense of the rice crop against insect pests. Ann N Y Acad 287:287295.

Pathak M D, Khush G S (1979) Studies of varietal resistance in rice to the brown planthopper at the International Rice Research Institute in Heong KL, Hardy B (Eds.) Brown planthopper: threat to rice production in Asia, International Rice Research Institute, Los Banos, Laguna, The Philippines. Pp. 285-301.

Peleman J D, Van der Voort J R R (2003) Breeding by design. Trends in plant science 8(7). pp.330-334.

Prahalada G D, Shivakumar N, Lohithaswa H C, Gowda D S, Ramkumar G, Kim S R, Ramachandra C, Hittalmani S, Mohapatra T, Jena K K (2017) Identification and fine mapping of a new gene, BPH31 conferring resistance to brown planthopper biotype 4 of India to improve rice, Oryza sativa L. Rice 10:41.

Qiu Y, Guo J, Jing S, Tang M, Zhu L, He G (2011) Identification of antibiosis and tolerance in rice varieties carrying brown planthopper resistance genes. Entomol Exp Appl 141:224231.

Qiu Y, Guo J, Jing S, Zhu L, He G (2012). Development and characterization of japonica rice lines carrying the brown planthopper-resistance genes BPH12 and BPH6. Theor Appl Genet 124: 485-494.

Qiu Y F, Cheng L, Liu F, Li R B (2013) Identification of a new locus conferring antixenosis to the brown planthopper in rice cultivar Swarnalata (Oryza sativa L.). Genet Mol Res 12:3201-3211.

Rahman M L, Jiang W, Chu S H, Qiao Y, Ham T H, Woo M O, Lee J, Khanam, M S, Chin J H, Jeung J U, Brar D S (2009) High-resolution mapping of two rice brown planthopper resistance genes, Bph20 (t) and Bph21 (t), originating from Oryza minuta. Theor Appl Genet 119:1237-1246.

Ramkumar G, Prahalada G D, Hechanova S L, Kim S R, Jena K K (2016) Exploring genetic diversity of rice cultivars for the presence of brown planthopper (BPH) resistance genes and development of SNP marker for Bph18. Plant Breed 135:301-308.

Ren X, Wang X, Yuan H, Weng Q, Zhu L, He G (2004) Mapping quantitative trait loci and expressed sequence tags related to brown planthopper resistance in rice. Mol Plant Breed 123:342-348.

Renganayaki K, Fritz A K, Sadasivam S, Pammi S, Harrington S E, McCouch S R, Kumar S M, Reddy A S (2002) Mapping and 
progress toward map-based cloning of brown planthopper biotype-4 resistance gene introgressed from into cultivated rice. Crop Sci 42:2112-2117.

RRDI (2018). Recommended Rice Varieties in Sri Lanka (1958-2016). (Research and Development Institute, Department of Agriculture, Bathalagoda, Ibbagamuwa, Sri Lanka, 2018)

Sangha J S, Chen Y H, Kaur J, Khan W, Abduljaleel Z, Alanazi M S, Mills A, Adalla C B, Bennett J, Prithiviraj B, Jahn G C (2013) Proteome analysis of rice (Oryza sativa L.) mutants reveals differentially induced proteins during brown planthopper (Nilaparvata lugens) infestation. Int J Mol Sci 14: 3921-3945.

Saxena R C, Barrion A A (1985) Biotypes of the brown planthopper Nilaparvata lugens (Stål) and strategies in deployment of host plant resistance. Int J Trop Insect Sci 6:271289.

Senthil-Nathan S, Choi M Y, Paik C H, Seo H Y, Kalaivani K (2009) Toxicity and physiological effects of neem pesticides applied to rice on the Nilaparvata lugens Stål, the brown planthopper. Ecotoxicol Environ Saf 72:1707-1713.
Sidhu G S, Khush G S (1978) Genetic analysis of brown planthopper resistance in twenty varieties of rice, Oryza sativa L. Theor Appl Genet 53: 199-203.

Singh R P, Huerta-Espino J, William H M (2005) Genetics and breeding for durable resistance to leaf and stripe rusts in wheat. Turk J Agric For 29: 121-127.

Stam P (1981) The theoretical proportion of the donor genome in near-isogenic lines of self-fertilizers bred by back crossing. Euphytica 30:227-238.

Stapley J H, May-Jackson Y Y, Golden W G (1979) Varietal resistance to the brown planthopper in the Solomon Islands in Heong K L, Hardy B (Eds.) Brown planthopper: threat to rice production in Asia. International Rice Research Institute, Los Banõs, Phillippines. Pp.233-239.

Suh J P, Cho Y C, Won Y J, Ahn E K, Baek M K, Kim M K, Kim B K, Jena K K (2015) Development of resistant gene-pyramided japonica rice for multiple biotic stresses using molecular marker-assisted selection. Plant Breed Biotechno 3:333-345.

Suh J P, Jeung J U, Noh T H, Cho Y C, Park S H, Park H S, Shin M S, Kim C K, Jena K K (2013) Development of breeding lines with three pyramided resistance genes that confer 
broad-spectrum bacterial blight resistance and their molecular analysis in rice. Rice 6:5.

Suh J P, Yang S J, Jeung J U, Pamplona A, Kim J J, Lee J H, Hong H C, Yang C I, Kim Y G, Jena, K K (2011) Development of elite breeding lines conferring Bph18 gene-derived resistance to brown planthopper (BPH) by markerassisted selection and genome-wide background analysis in japonica rice (Oryza sativa L.). Field Crops Res 120: 215-222.

Sun L, Su C, Wang C, Zhai H, Wan J (2005) Mapping of a major resistance gene to the brown planthopper in the rice cultivar Rathu Heenati

Breed Sci 55:391-396.

Tamura Y, Hattori M, Yoshioka H, Yoshioka M, Takahashi A, Wu J, Sentoku N, Yasui H (2014) Map-based cloning and characterization of a brown planthopper resistance gene BPH26 from Oryza sativa L. ssp. indica cultivar ADR52. Sci Rep 4:5872.

Tanaka K, Endo S, Kazano H (2000) Toxicity of insecticides to predators of rice planthoppers: spiders, the mirid bug and the dryinid wasp. Appl Entomol Zool 35:177-187.

Tester M, Langridge P (2010) Breeding technologies to increase crop production in a changing world. Science 327:818-822.
Thabuis A, Palloix A, Servin B, Daubeze A M, Signoret P, Lefebvre V (2004) Markerassisted introgression of 4 Phytophthora capsici resistance QTL alleles into a bell pepper line: validation of additive and epistatic effects. Mol Breed 14:9-20.

Thamarai M, Soundararajan R P (2017) Evaluation of antibiosis resistance to brown planthopper, Nilaparvata lugens (Stal) in rice. J Entomol Zool Stud 5:954-957.

Tingey W M (1981) The environmental control of insects using plant resistance [Genetic diversity]. CRC handbook of pest management in agriculture (USA).

Visarto P, Zalucki M P, Nesbitt H J, Jahn G C (2001) Effect of fertilizer, pesticide treatment, and plant variety on the realized fecundity and survival rates of brown planthopper, Nilaparvata lugens (Stål) (Homoptera: Delphacidae) generating outbreaks in Cambodia. J Asia Pac Entomol 4:75-84.

Voramisara V, Sa-nguansaj T (1994) Chai Nat 1 , a new approved rice variety. Warasan Wichakan Kaset 23: 185-190.

Wan B, Zha Z, Li J, Xia M, Du X, Lin Y, Yin D (2014) Development of elite rice restorer lines in the genetic background of R022 possessing tolerance to brown planthopper, 
stem borer, leaf folder and herbicide through marker-assisted breeding. Euphytica 195:129-142.

Wang X, Zhang M, Feng F, He R (2015) Differentially regulated genes in the salivary glands of brown planthopper after feeding in resistant versus susceptible rice varieties. Arch Insect Biochem Physiol 89:6986.

Wang X L, He R F, He, G C (2005) Construction of suppression subtractive hybridization libraries and identification of brown planthopper-induced genes. J Plant Physiol 162:1254-1262.

Wang Y, Cao L, Zhang Y, Cao C, Liu F, Huang F, Qiu Y, Li R, Lou X (2015) Map-based cloning and characterization of $\mathrm{BPH} 29$, a B3 domaincontaining recessive gene conferring brown planthopper resistance in rice. J Exp Bot 66:6035-6045.

Wang Y, Chen J, Zhu Y C, Ma C, Hung Y, Shen J (2008) Susceptibility to neonicotinoids and risk of resistance development in the brown planthopper, Nilaparvata lugens (Stål) (Homoptera: Delphacidae). Pest Manag Sci 64:1278-1284.

Wang Y, Li H, Si Y, Zhang H, Guo H, Miao X (2012) Microarray analysis of broad- spectrum resistance derived from an indica cultivar Rathu Heenati. Planta 235:829-840.

Wei Z, Hu W, Lin Q, Cheng X, Tong M, Zhu L, Chen R, He G (2009) Understanding rice plant resistance to the brown planthopper (Nilaparvata lugens): a proteomic approach. Proteomics 9: 2798-2808.

Wenzl P, Carling J, Kudrna D, Jaccoud D, Huttner E, Kleinhofs A, Kilian A (2004) Diversity Arrays Technology (DArT) for whole-genome profiling of barley. Proc Natl Acad Sci USA 101: 9915-9920.

Wissuwa M, Wegner J, Ae N, Yano M (2002) Substitution mapping of Pup1: a major QTL increasing phosphorus uptake of rice from a phosphorus-deficient soil. Theor Appl Genet 105: 890-897.

Wu H, Liu Y, He J, Liu Y, Jiang L, Liu L, Wang C, Cheng X, Wan J (2014) Fine mapping of brown planthopper (Nilaparvata lugens Stål) resistance gene $B p h 28(\mathrm{t})$ in rice (Oryza sativa L.). Mol Breed 33:909-918.

Wu J C, Qiu H M, Yang G Q, Liu J L, Liu G J, Wilkins R M (2004) Effective duration of pesticide-induced susceptibility of rice to brown planthopper (Nilaparvata lugens Stål, Homoptera: Delphacidae), and physiological and biochemical changes in rice plants 
following pesticide application. Int J Pest Manag 50:55-62.

Xiao C, Hu J, Ao Y T, Cheng M X, Gao G J, Zhang Q L, He G C, He Y Q (2016) Development and evaluation of near-isogenic lines for brown planthopper resistance in rice cultivar 9311. Sci Rep 6:38159.

Yang H, Ren X, Weng Q, Zhu L, He G (2002) Molecular mapping and genetic analysis of a rice brown planthopper (Nilaparvata lugens Stål) resistance gene. Hereditas 136:39-43.
Yang L, Li R B, Li Y R, Huang F K, Chen Y Z, Huang S S, Huang,L F, Liu C, Ma Z F, Huang D H, Jiang, J J (2012) Genetic mapping of bph20 (t) and bph21 (t) loci conferring brown planthopper resistance to Nilaparvata lugens Stål in rice (Oryza sativa L.). Euphytica 183:161-171.

Zhao Y, Huang J, Wang Z, Jing S, Wang Y, Ouyang Y, Cai B, Xin X F, Liu X, Zhang C, Pan Y (2016) Allelic diversity in an NLR gene BPH9 enables rice to combat planthopper variation. Proc Natl Acad Sci 113:1285012855. 